\title{
Efficacy of Polytechnic Students' Interpersonal Communication Skills
}

\author{
Zaharatul Akmar Ahmad Zainuddin and Suzanah Selamat \\ (Universiti Teknologi MARA, Shah Alam, Malaysia) \\ doi:10.7575/aiac.alls.v.3n.2p.76
}

\begin{abstract}
Every year polytechnics in Malaysia produce thousands of graduates in vocational areas, however, these graduates have to strive in a competitive job market against graduates from other tertiary institutions. This study aims to investigate polytechnic students' efficacy on their communication skills. These skills are crucial in determining their chances for employment and would also enable them to perform effectively at workplace. Final semester students from Politeknik Sultan Salahuddin Abdul Aziz Shah $(n=120)$ were asked to assess their own communication skills ability using the Communication Skills self-assessment questionnaire. Findings indicate that polytechnic students are quite confident in their ability to communicate effectively at workplace and job interviews. However, interviews with potential employers indicate differently. Implications of the study include a call for the evaluation of the English proficiency courses currently being implemented in Malaysian polytechnics.
\end{abstract}

\section{Introduction}

Communication is the transfer of information from one person to another. It is an important and basic skill that polytechnic students have to build in order to make them marketable once they complete their studies. Having good communication skills will help the students to secure a job, build a good relationship with people they come in contact with in their working lives and it is also vital to their career development. Therefore, students need to be taught how to communicate effectively in a work environment especially, related to their areas. They need to convey good communication skills that are also related to their technical knowledge. Therefore, these students will be able to excel in their studies and future career. Mehta \& Mehta (2007) argue that to be successful in any field one needs to know and understand how to communicate effectively. According to them, professionals who have a strong hold on communication skills are considered assets for any business organization. In the Globalization era, good communication skills are keys to career success. 
However, a great deal of communication is of the non-verbal form as opposed to the oral and written forms. This type of communication includes facial expressions, eye contact, tone of voice, body posture and motions, and positioning within groups.

A study by Porter (2000) reports that employers argue that college students conducting job search processes do not possess the skills they seek including oral communication skills. Employers believe that students lack the basic skills of speaking and listening (Porter, 2000). It seems that there is a clear mismatch between the communication skills that employers seek and the communication skills that students offer. Hence, this study is carried out to determine whether engineering students in Malaysian polytechnics possess interpersonal communication skills in order to function effectively at the work place.

\section{Role and importance of English language for polytechnic students}

The Malaysian education system aims to produce students who have excellent communication skills, and are competent in languages, especially English. Although the national language is Bahasa Melayu, English is established as its second language and is regarded highly as it is the language of trade and used in most business dealings. In Malaysia, all students are required to learn English in primary and secondary schools. Hence, Malaysian students would have received 11 years of formal learning of the language. Students are expected to be competent in the language once they finish their formal schooling as most institutions of higher learning use English as their language of instruction. This competency should give them an edge in a competitive job market.

Polytechnic education in Malaysia was introduced in 1969 with the vision to produce semiprofessionals in technical, commerce and hospitality areas to fill in the needs of the nation's growing industries. This system allows an alternative route for the students who face difficulty in pursuing the normal school streams. With the increase of multinational companies setting their practices in Malaysia, polytechnics are required to produce graduates who are able to communicate effectively in English. Therefore, all polytechnic students are required to undergo six semesters of English programmes as well as one semester of practical training at the selected company to gain exposure in the working environment. Other than these programmes, the students are also required to take a soft skills class in their third semester before they undergo their practical training. With the amount of formal learning of 
the English language and the soft skills class that students have taken, it is expected that these students would be able to express themselves effectively once they have graduated. These programmes are supposed to help them secure employment easily. However, in reality, graduates are finding it difficult to communicate during job interviews and when they are lucky enough to secure a job they are unable to advance themselves due to a lack of communication skills.

\section{Need for communication skills for engineering professionals}

Engineering students require communication skills to enhance their technological knowledge and thereby excel in their career (Srigayathridevi \& Thamaraiselvi, 2006). According to Mehta \& Mehta (2007), graduate engineers do not have good communication skills and fail miserably to fulfill the basic requirements of organizations. This is true of polytechnic students' in Malaysia as many employers who employ polytechnic graduates have voiced their concerns that these graduates have great difficulties in communicating effectively at work despite having excellent technical knowledge in their areas. This problem is especially evident in students taking engineering courses in Malaysian polytechnics.

Scholars have tried to describe the necessary components of engineering education in colleges to include not just technical knowledge but also take into consideration skills that these graduates would be required to use at their workplace. Mehta \& Mehta (2007) point out that engineering professionals need communication skills for the following reasons: (pp. 3-4)

1. To express and share their experience, knowledge, ideas and thoughts in an effective manner for the common benefit of the society.

2. To aspire to a bright academic career growth.

3. To secure a higher level of position in the related jobs.

4. To attain timely promotion and other benefits at their work place.

5. To lead the team from the front.

6. To develop a very healthy working environment and interpersonal communication skills.

7. To harness understanding and create harmony.

8. To pursue advanced or higher level of studies.

9. To work in a globalized and multilingual culture.

10. To sharpen presentation, writing, negotiation, intrapersonal skills etc. 
Meanwhile, Rugarcia, Felder, Woods and Stice (2000) argue that the profile of engineering education should be categorised into three components: (1) their knowledge - the facts they know and concepts they understand; (2) the skills - they use in managing and applying their knowledge, such as computation, experimentation, analysis, synthesis/design, evaluation, communication, leadership, and teamwork; (3) the attitudes that dictate the goals toward which their skills and knowledge will be directed - personal values, concerns, preferences and biases (p. 20).

A study by Seat (1999) highlights the fact that engineering students need to learn teaming and interacting skills as part of their education. This includes soft skills and group interaction to be discussed frequently in classrooms in terms of learning styles, improved learning in groups, socialization for working with others, and interpersonal skills.

\section{Research objectives and questions}

The study aims to investigate polytechnic students' attitude towards interpersonal communication skills at the workplace and their level of awareness in terms of workplace etiquette, paralanguage and conversation skills.

The study aims to answer these questions:

a. What are the polytechnic students' attitudes towards interpersonal communication skills at the workplace?

b. What is the level of students' awareness towards workplace etiquette, paralanguage and conversation skills?

\section{Methodology}

\section{Instrument}

A questionnaire adapted from the Interpersonal Communication Skills Inventory (Learning Dynamics, 2002) was used to identify participants' knowledge on Interpersonal Communication Skills. The questionnaire is designed to help the students to evaluate their interpersonal communication skills and style while at the same time provide helpful tips in becoming a good communicator and team player.

The questionnaire comprises of 23 questions divided into 3 components: workplace etiquette, paralanguage and conversation skills. Krizan, Logan \& Merrier (2007) argued that these components make up an individual's interpersonal skills: 
i. Workplace etiquette

Work etiquette basically "incorporates all type of manners and behaviour in relation to work dealings such as how you come across as an individual, how you relate to others both within your own organisation and externally and how you make use of the tools with which you can communicate", (http://www.worketiquette.co.uk). As eiquette is not fixed or rigid, people who are new in an office or workplace may find it difficult to understand. Other than this, different workplaces differ when it comes to what is considered acceptable behaviour and conduct and the formality of etiquette also varies between companies.

ii. Paralanguage

According to Singh (2003), paralanguage is "closest to actual verbal (oral) communication and almost always accompanies body language..." (pg 152). Paralanguage is important in communication because without it, it is difficult for words to convey their intended meaning.

iii. Conversation skills

According to Krizan, Logan \& Merrier (2007) "relationship begins with conversations." (pg.366). Krizan et al. highlight the importance of conversation as a valuable business tool since it is essential for good customer service and forms the foundation for workplace interactions among employees.

Each question was followed by three answers, one of which was the best answer. The best answer was awarded three points while other answers were given one point.

To gain insight into employers' comments and views regarding polytechnic students performance at the workplace, data from Industrial Dialogue 2008 were also referred to in this study. Industry Dialogue 2008 was organized by the Department of Polytechnic and Community College Education (DPCCE), Ministry of Higher Education (MoHE). The objectives of this dialogue were to promote and strengthen industry-education collaboration so as to develop a common understanding of the industry's needs and how polytechnics and community colleges can fulfil those needs for the national as well as the international market. 


\section{Participants}

The questionnaires were distributed to final semester students undergoing Diploma in Engineering at Politeknik Sultan Salahuddin Abdul Aziz Shah. Out of 120 questionnaires distributed, only 90 were completed and analysed.

\section{Results and analysis}

Data from the questionnaire were analysed using the SPSS version 17.0. Based on the descriptive analyses the following results were found:

Question 1: What are the polytechnic students' attitudes towards interpersonal communication skills at the workplace? Table 1 summarises the result of the students' attitudes regarding interpersonal communication skills at the workplace:

Table 1: Students' attitude regarding interpersonal communication skills

\begin{tabular}{|c|c|c|}
\hline No. & Items & $\%$ \\
\hline i. & equalize participation in the conversation with others. & $\underline{46}$ \\
\hline ii. & introduce themselves with a smile and offer a handshake. & $\overline{69}$ \\
\hline iii. & warm-up new conversations with small talks. & 53 \\
\hline iv. & make an effort to remember and use peoples' names. & 61 \\
\hline $\mathrm{v}$. & frequently use courtesy words and phrases. & 72 \\
\hline vi. & do not say anything if a colleague has put on weight. & $\underline{28}$ \\
\hline vii. & smile at appropriate times while conversing. & $\overline{64}$ \\
\hline viii. & make eye contact while conversing. & 52 \\
\hline ix. & nod head at appropriate times while conversing. & 56 \\
\hline $\mathrm{x}$. & stand two to three feet away from the person while conversing. & $\underline{44}$ \\
\hline xi. & sit while talking to a person who is sitting. & 67 \\
\hline xii. & lean slightly forward and face body towards speaker while listening to them. & 53 \\
\hline xiii. & cross legs facing speaker. & $\underline{32}$ \\
\hline xiv. & smile and use humor at appropriates times. & $\overline{66}$ \\
\hline $\mathrm{XV}$. & wrap-up with a closing statement to end the conversation & $\underline{47}$ \\
\hline xvi. & listen for meaning and ask questions while listening to speakers. & $\overline{57}$ \\
\hline xvii. & $\begin{array}{l}\text { relate to a person's feelings and show sensitivity to his or her misfortune when someone } \\
\text { talks about an unfortunate or sad experience. }\end{array}$ & 52 \\
\hline Xviii. & talk about and focus on positive (good) aspects when discussing a topic. & 76 \\
\hline xix. & lead-in with a positive comment first when they have a negative opinion or comment. & 63 \\
\hline $\mathrm{xx}$. & take note where to improve when they receive unfavorable feedback. & 79 \\
\hline xxi. & $\begin{array}{l}\text { focus on a person's observable work or behavior and offer suggestions when giving a } \\
\text { negative feedback. }\end{array}$ & $\underline{40}$ \\
\hline xxii. & talk with a person alone in a private place when giving a negative feedback. & 70 \\
\hline xxiii. & $\begin{array}{l}\text { listen first, ask questions for clarification, then disagree non-judgmentally when they } \\
\text { disagree with a person }\end{array}$ & 60 \\
\hline
\end{tabular}

Overall, the results show that, participants have achieved high scores on their knowledge regarding interpersonal communication at the workplace. Items regarding giving and receiving feedback have high scores, i.e. frequently use courtesy words and phrases (72\%), talk about and focus on positive (good) aspects when discussing a topic (76\%), take note 
where to improve when they receive unfavorable feedback $(79 \%)$ and talk with a person alone in a private place when giving a negative feedback $(70 \%)$.

On the other hand, not say anything if a colleague has put on weight (28\%) and crossing legs facing speaker $(32 \%)$ have the lowest scores. Perhaps, this is due to cultural differences and lack of participants' knowledge of western culture, for example, crossing one's legs is a permissible act in the west but not in the east.

Question 2a: What is the level of students' awareness towards workplace etiquette?

Figure 1 below summarises the result of the students' level of awareness towards workplace etiquette.

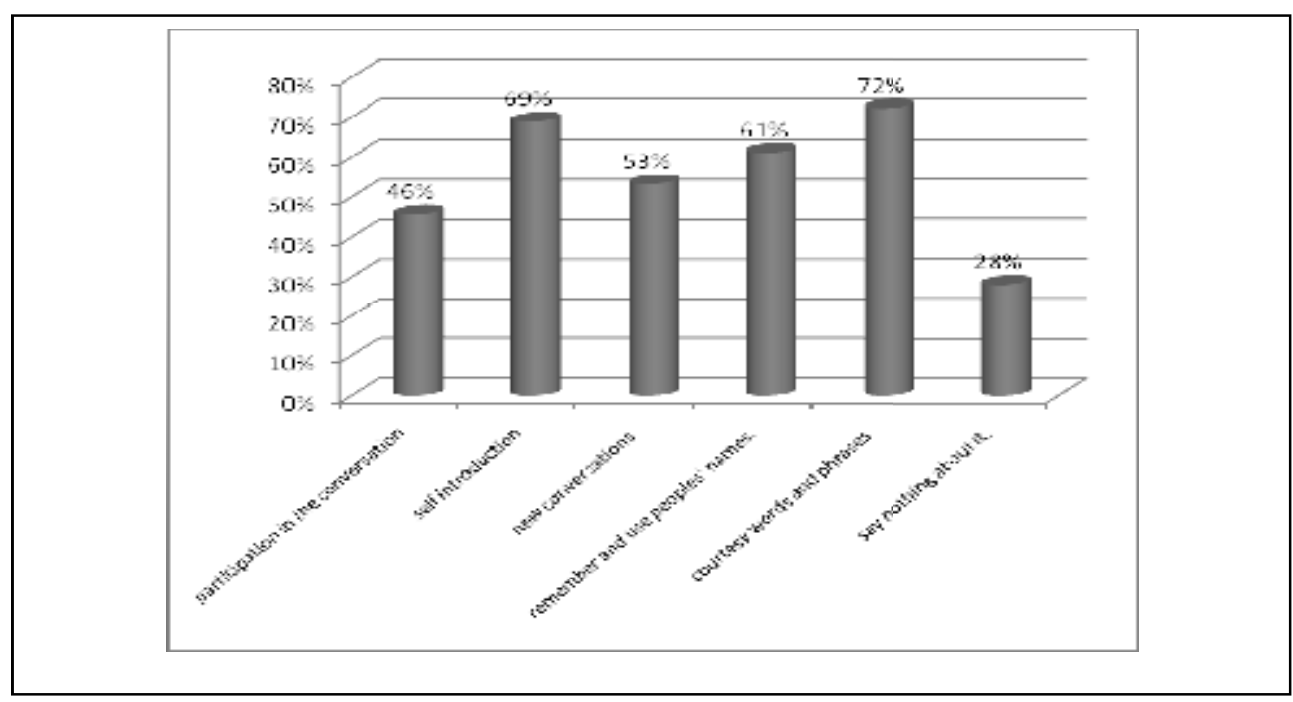

Figure 1: Etiquette

The results show that participants have a mixed level of awareness of workplace etiquette. They know that they have to use 'courtesy words and phrases during conversations' (72\%) and 'smile and offer a handshake while introducing themselves' (69\%). This could be because polytechnics students are given training on how to attend and perform at an interview as part of their course requirements.

However, participants were not aware that they should say anything if a colleague has put on weight $(28 \%)$. This is probably due to the fact that discussions regarding a person's weight are not considered offensive in Malaysian culture and can indicate a person's concern about someone's health. 
Question 2b: What is the level of students' awareness towards paralanguage?

Figure 2 summarises the result of the students' level of awareness towards paralanguage.

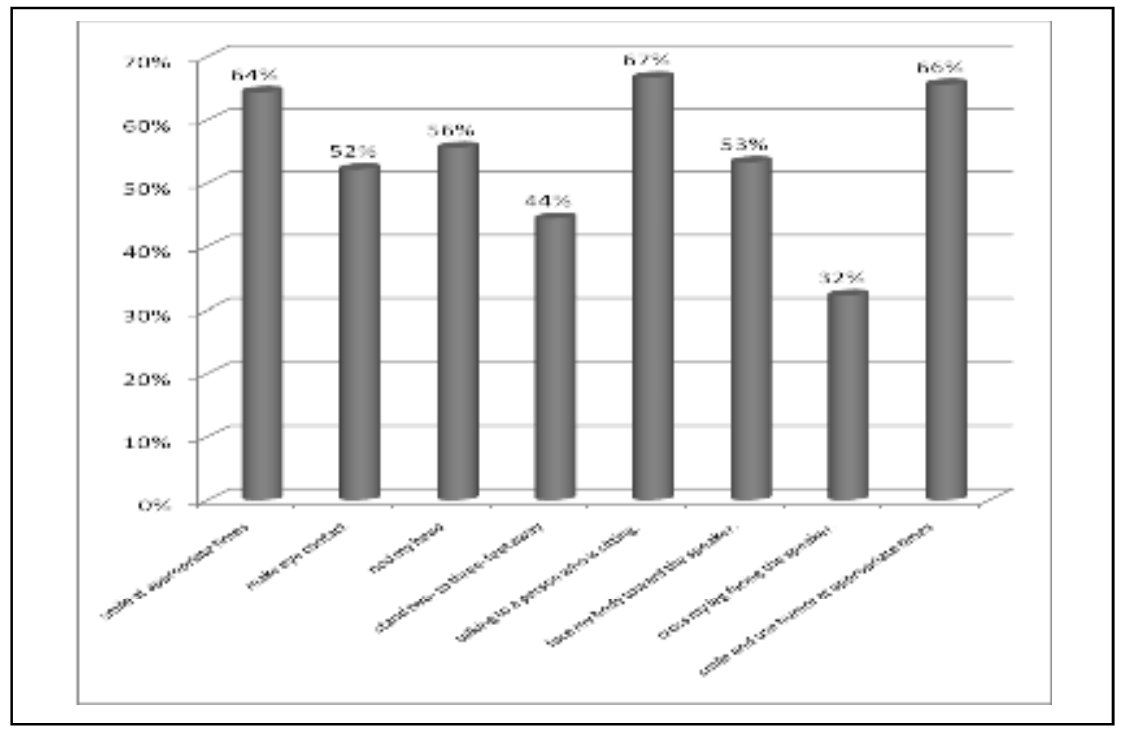

Figure 2: Level of awareness towards paralanguage

Overall, the participants scored moderately on their knowledge of paralanguage at work place. Items with the highest scores are 'sitting while talking to a person who is sitting' (67\%) and 'smiling and using humor at appropriates times' (66\%). Meanwhile, participants do not realize that 'crossing legs when facing a speaker' (32\%) can be considered as inappropriate.

Question 2c: What is the level of students' awareness towards conversation skills? Figure 3 below summarises the result of the students' level of awareness towards conversation skills.

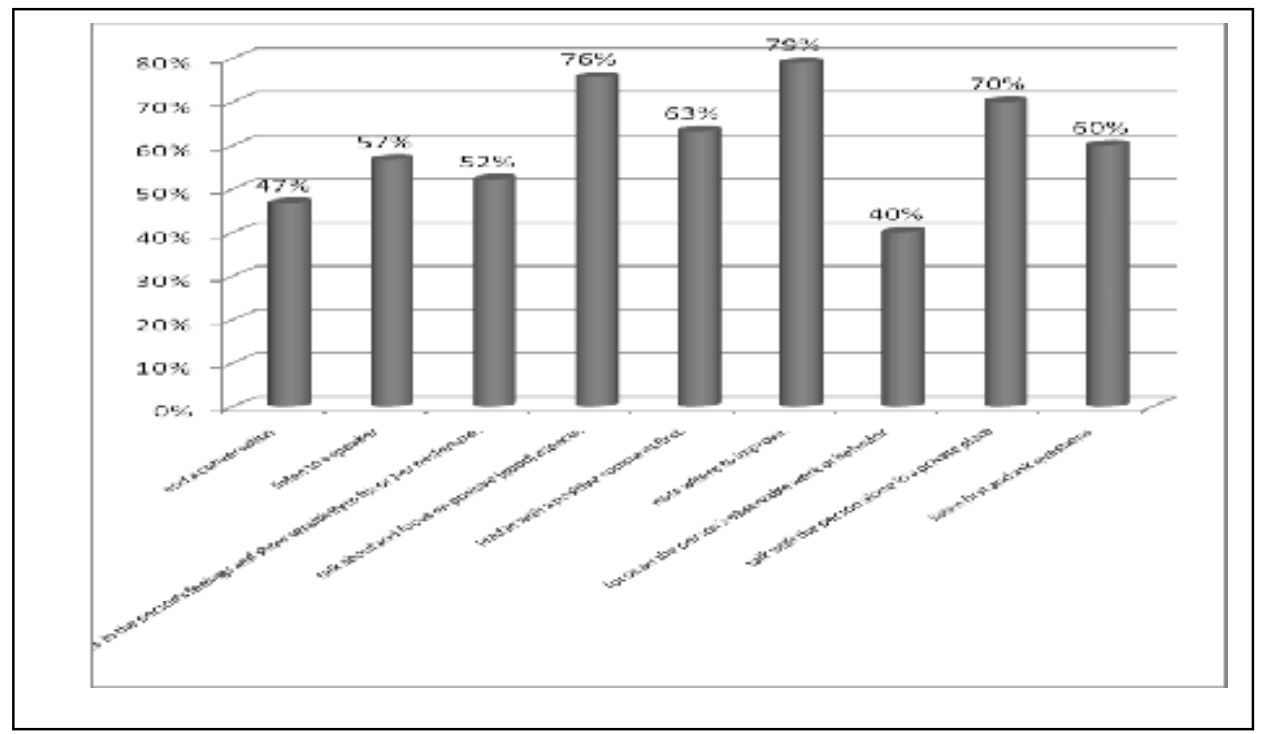

Figure 3: Level of awareness towards conversation skills 
In general the participants are quite knowledgeable on how to handle conversations. Items with the highest scores are 'taking note where to improve when they receive unfavorable feedback' (79\%) and 'talking about and focusing on positive (good) aspects when discussing a topic' $(76 \%)$.

The lowest items scored are 'judging a person when giving a negative feedback' (40\%) and 'wrapping-up with a closing statement to end the conversation' (47\%). This seems to indicate that the participants do not know how to end a conversation appropriately. They also do not know that they should focus on the person's observable work or behaviour when giving negative feedback.

\section{Conclusion and recommendations}

From the results above, the students seem to be quite knowledgeable on interpersonal communication skills and know how to communicate appropriately at the workplace except for a few situations, i.e. items vi, xiii and xxi. The participants should learn more on the appropriate etiquette and body language of western culture which is different compared to the Malaysian culture. Future graduates need to be exposed to other cultures so that they would be able to socialise and communicate effectively at the workplace.

Even though polytechnic students are briefed on how to attend job interviews, employers comment that the students do not know how to apply this knowledge during actual interviews. This also happens when they communicate with their superiors and colleagues. It is concluded that there is a mismatch of the efficacy of communication skills between polytechnic students and potential employers. Hence, some changes in the way that engineering students in polytechnics are trained should be reviewed.

"Communication skills can be developed by rigorous training programmes and a lot of practice work" (Mehta \& Mehta, 2007pg?). Mehta \& Mehta (2007) suggest adding social science subjects into engineering syllabus which will promote both oral and written communication skills. This is also supported by Woods et al., (2000) who suggest that the development of any skill is best facilitated by giving students practice and not by simply talking about or demonstrating what to do. 
Hence, Malaysian polytechnics should conduct a review of their English language teaching practices as well as syllabus. It is suggested that the English language classes should incorporate the following changes:

i. more real life communication practices

ii. more emphasis on English for Occupational Purposes (EOP)

iii. assessment for English language must reflect the above policy

It is also suggested that the co-curriculum activities of polytechnic students should be reviewed to incorporate greater students' involvement in their institutions. This is to ensure that polytechnic students will also gain greater experience and personal development while achieving technical knowledge at the institutions.

Results of this study show that polytechnic students are aware of the importance of interpersonal communication skills for their future career. However, they do not seem to take any initiative to improve their knowledge in this area. This is probably due to the fact that Malaysian students are used to being 'spoon fed' by teachers and lecturers. This is supported by a study carried out by Ambigapathy \& Aniswal (2005) which state that in general, student's performance and abilities have been gradually decreasing over the years. According to Ambigapathy \& Aniswal (2005) university students remain passive learners, accepting what is given without any question. Opportunity for students to interact, debate and discuss is further reduced with the increasing number of students in each class. These learning activities are essential to develop communicative, collaborative and critical thinking skills. 


\section{References}

Ambigapathy, P. \& Aniswal, A.G. (2005). University curriculum: An evaluation on preparing graduates for employment. National Higher Education Research Institute, Pulau Pinang, Malaysia.

Interpersonal Communication Skills Inventory (Learning Dynamics, 2002) http:www.nal.usda.gov/wicworks/Sharing_Center/CT/csmodule/Inventory.pdf.

Krizan, A. C., Logan, J. \& Merrier, P. (2007). Bussiness Communication. South Western Pub.

Mehta, D. \& Mehta, N. K. (2007). Communication skill for Engineering profesionals. Adit Journal., 4, 1, pg. 8995.

Porter, R. (2000). Levels of effectiveness of communication skills used by college students during the job search process. (Unpublished Masters of Arts in Education Thesis, Virginia Polytechnic Institute and State University).

Rugarcia, A.,. Felder, R. M., Woods, D.R. \& Stice, J. E. (2000). The future of Engineering education I. A vision for a new century. Chemical Engineering. Education, 34(1), 16-25 .

Seat, E. \& Lord, S. M. (1999). Enabling effective Engineering teams: A program for teaching interaction skills. Journal of Engineering Education, 1, 1, pg. 1-6.

Singh, A. (2003), Business Communication, Anmol Publications Pvt. Ltd., New Delhi.

Srigayathridevi, K. \& Thamaraiselvi, R. (2006). Communication skills among the final year Engineering students in an autonomous Engineering college in Coimbatore, India: An Evaluation. The Journal of Nepalese Business Studies, 3. 1. Pg. 114-119.

The Department of Polytechnics and Community College Education, M. O. (2008). Industrial Dialogue 2008.

Woods, D. R. Felder, R. M., Rugarcia, A. \& Stice, J. E.(2000). The future of Engineering education III.

Developing critical skills. Chemical EngineeringEducation, 34(2), 108-117 . 